\title{
LA PROTECCIÓN PENAL AMBIENTAL: USO ILEGÍTIMO DE LAS FUNCIONES SIMBÓLICAS DEL DERECHO*
}

\author{
MARTHA ISABEL GÓMEZ VÉLEZ ${ }^{* *}$ \\ Presentado: junio 2 de 2014 • Aprobado: junio 30 de 2014
}

\section{Resumen}

Este escrito intenta ubicar de manera más especifica la intervención penal dentro de la protección nacional e internacional del medio ambiente y los recursos naturales, y la revisión de si esta tutela sí tiene aplicación efectiva en la realidad, tarea que se desarrollará verificando, en primer lugar, cuál es la solución penal que se pone en práctica para garantizar la tutela ambiental; en segundo lugar, la caracterización del tipo de Derecho penal que se emplea para esta tutela, que supone analizar el concepto de bien jurídico colectivo y que se enmarca en una discusión general respecto de la protección del medio ambiente en el marco de una concepción ecocéntrica o antropocéntrica. En tercer lugar, reuniendo las exposiciones anteriores, se mostrarán las posturas sobre el Derecho penal simbólico y las razones de por qué se considera que su uso es ilegítimo e ineficaz a la luz de la efectiva protección del bien jurídico del medio ambiente y los recursos naturales.

Este artículo es producto final del proyecto de investigación denominado "Funciones simbólicas del Derecho penal ambiental", adscrito al grupo de investigación Ratio Juris de la Facultad de Derecho de la Universidad Autónoma Latinoamericana, Medellín, Colombia, en la línea de investigación Globalización, Derechos Humanos y Políticas Públicas. La autora es la investigadora principal.

** Abogada de la Universidad de Antioquia; especialista en Derecho penal de la Universidad EAFIT y magíster en Derecho de la Universidad de Antioquia. Profesora e investigadora de tiempo completo del área de Derecho penal en la Facultad de Derecho de la Universidad Autónoma Latinoamericana, adscrita al grupo de investigación Ratio Juris. Docente de cátedra de la Facultad de Derecho y Ciencias Políticas de la Universidad de Antioquia (martha.gomez@unaula.edu.co). 
Palabras clave: delitos ambientales, expansión del Derecho penal, Derecho penal simbólico, bienes jurídicos colectivos, funciones latentes y manifiestas del Derecho.

\title{
CRIMINAL ENVIRONMENTAL PROTECTION: UNLAWFUL USE OF SYMBOLIC FUNCTIONS OF LAW
}

\begin{abstract}
This paper attempts to locate more specific the criminal intervention in the national and international environmental protection and natural resources, and review whether this protection does have effective application in reality, a task that will run checking first what is the penal solution is implemented to ensure environmental protection; second, the characterization of the type of criminal law is used for this protection, which involves analyzing the legal concept of collective good, which is part of a general discussion about the protection of the environment in the context of an ecocentric conception or anthropocentric; and thirdly, gathering the previous exhibitions, show the positions on the symbolic criminal law and the reasons why it is considered that its use is illegitimate and ineffective in light of the effective protection of good environmental and natural resources law.
\end{abstract}

Keywords: environmental crimes, expansion of criminal law, symbolic criminal law, collective legal interests, latent and manifest functions of law.

\section{CRIMINEL PROTECTION DE L'ENVIRONNEMENT: UTILISATION ILLICITE FONCTIONS DE DERECHO SYMBOLIQUE}

\section{Résumé}

Ce document tente de localiser l'intervention afin pénale, plus spécifique dans la protection de l'environnement national et international et des ressources naturelles, et d'examiner si cette protection a une ap- 
plication effective dans la réalité, une tâche qui se déroulera c'est vérifier d'abord quelle est la solution pénale mis en œuvre pour assurer la protection de l'environnement; deuxièmement, la caractérisation du type de droit pénal est utilisé pour cette protection, qui consiste à analyser la notion juridique de bien collectif, qui fait partie d'une discussion générale sur la protection de l'environnement dans le cadre d'une conception ecocentric ou anthropocentrique; et troisièmement, regroupant les précédentes expositions, montrer les positions sur le droit pénal symbolique et les raisons pour lesquelles il est considéré que son utilisation est illégitime et inefficace à la lumière de la protection effective de la bonne loi d'environnement et des ressources naturelles.

Mots-clés: crimes contre l'environnement, extension du droit penal, Droit pénal symbolique, intérêts juridiques collectives, fonctions latentes et manifestes du Droit.

\section{PROTEZIONE PENALE DELL'AMBIENTE: USO ILLEGALE DELLE FUNZIONI SIMBOLICHE DEL DIRITTO}

\section{Riassunto}

Questo scritto tenta di individuare in maniera più specifica l'intervento penale entro la protezione nazionale ed internazionale dell' ambiente e delle risorse naturali, e la recensione di se questa tutela si ha applicazione efficace in realtà, compito che si svilupperà controllando, In primo luogo, qual è la soluzione penale che si mette in pratica per garantire la protezione dell'ambiente; in secondo luogo, la caratterizzazione del tipo di diritto penale, che è usato per questa protezione, cosa che porta a analizzare il concetto di bene giuridico collettivo, che si presenta in una discussione generale in merito della protezione dell' ambiente nel quadro di una concezione ecócentrica o antropocentrica; e in terzo luogo, raccogliendo le precedenti mostre, si vedránno le posizioni sul diritto penale simbolico e le ragioni del perché è considerato che il suo uso é illegittimo ed inefficace alle luce della l'efficace protezione del bene giuridico ambiente e risorse naturali. 
Parole chiave: Reati ambientali, espansione del diritto penale, Diritto penale simbolico, beni giuridici collettivi, funzioni latente e manifesta del Diritto.

\section{A PROTEÇÃO PENAL AMBIENTAL: USO ILEGÍTIMO DAS FUNÇÕES SIMBÓLICAS DO DIREITO}

\section{Resumo}

Este texto pretende localizar de maneira mais específica a intervenção penal dentro da proteção nacional e internacional do meio ambiente e os recursos naturais, e a revisão no caso desta tutela tiver aplicação efetiva na realidade, tarefa que vai se desenvolver pela verificação, em primeiro lugar, de qual é a solução penal posta em prática para garantir a tutela ambiental. Em segundo lugar, a caracterização do tipo de direito penal que é empregado para essa tutela, o que supõe a analise do conceito de bem jurídico coletivo, que é enquadrado em uma discussão geral a respeito da proteção do meio ambiente no marco de uma concepção eco-centrista ou antropo-centrista; e em terceiro lugar, reunindo as exposições anteriores, vão ser mostradas as posturas sobre o Direito penal simbólico e as razões do por que o seu uso é considerado ilegítimo e ineficaz na perspectiva da proteção efetiva do bem jurídico meio ambiente e recursos naturais.

Palavras chave: delitos ambientais, expansão do Direito penal, Direito penal simbólico, bens jurídicos coletivos, funções latentes e manifestadas do Direito. 


\section{INTRODUCCIÓN}

Este escrito constituye el producto final del trabajo de investigación "Funciones simbólicas del Derecho penal ambiental" inscrito en el grupo de investigación Ratio Juris de la Universidad Autónoma Latinoamericana y desarrollado desde agosto de 2013 hasta junio de 2014. El propósito del texto es verificar la pertinencia y necesidad de la intervención penal en la protección efectiva del medio ambiente y los recursos naturales.

Para el logro de este objetivo se trabajó desde una perspectiva cualitativa, que implica tener en cuenta los fenómenos sociales que rodean la protección ambiental, en especial el conflicto colombiano, considerado un factor determinante en la creación y aplicación de políticas públicas nacionales para la tutela ambiental. Esta exploración se realizó a través del examen de la bibliografía sobre el tema y de las políticas y normas jurídicas al respecto. Adicionalmente, como se trata de un análisis político-criminal, el estudio asume una mirada valorativa de esa tutela penal a la luz de los principios político-criminales que limitan el ius puniendi.

El desarrollo de este proyecto precisó del diseño de la siguiente hipótesis: la deficiente protección del medio ambiente que se logra con el uso de la herramienta penal y que plantea que el Derecho penal ambiental es un mecanismo simbólico que se convierte en obstáculo a la efectiva defensa de los componentes ambientales y quebranta los principios fundamentales del Derecho penal liberal.

\section{SOLUCIÓN PENAL PARA LA PROTECCIÓN AMBIENTAL}

Antes de abordar la forma como el Derecho penal ha asumido la protección del ambiente, es importante mencionar que este escrito parte de un concepto de Derecho penal mínimo, ${ }^{1}$ que hace referencia a una postura que predica que, de acuerdo con el carácter de ultima ratio del mismo, el ius

1 Esta postura tiene dos vertientes importantes, la primera se puede hallar en el "garantismo penal", de Luigi Ferrajoli, que propone la mínima intervención penal, la mínima aplicación de violencia estatal y la ampliación del concepto de libertad para ser aplicado a todos los ciudadanos sin excepción, incluidos aquellos que llevan a cabo conductas delictivas. También se pueden incluir aquî las posturas de la Escuela de Frankfurt, representada especialmente por Winfried Hassemer, ya que, a pesar de no negarse a la protección de nuevos intereses por la vía penal, dejan claro que el problema es que se use desmesuradamente la herramienta penal para proteger bienes jurídicos que carecen de materialidad, en la medida que no están conectados con la protección de la persona. Las anteriores posturas se pueden ampliar dentro de este contexto en Sotomayor (2009). 
puniendi estatal debe intervenir sólo en última instancia, una vez han intervenido los demás mecanismos estatales para la atención de toda problemática social que se debe controlar (aspecto subsidiario), pero además, sólo debe hacerlo para proteger los bienes jurídicos que se consideran más importantes, en especial, aquellos que están en estrecha relación con la protección del individuo y frente a los ataques más lesivos (carácter fragmentario) mediante el respeto de todas las garantías jurídico penales.

A pesar de lo anterior, la creciente criminalización de conductas que atentan contra la mínima intervención penal ha implicado que el Derecho penal se inmiscuya en asuntos que no le competen y se convierta en herramienta de acción principal para la resolución de conflictos sociales, fenómeno que puede ser ubicado dentro del contexto de expansión del Derecho penal frente a la existencia de sociedades de riesgo. ${ }^{2}$

Respecto del fenómeno expansivo, Silva (2006: 11) manifiesta que debe tenerse en cuenta la posibilidad de que éste se presente, al menos en parte, por las siguientes razones: "A la aparición de nuevos bienes jurídicos -de nuevos intereses o de nuevas valoraciones de intereses preexistentes-, y al aumento de valor experimentado por algunos de los que existían con anterioridad, que podría legitimar su protección a través del Derecho penal". ${ }^{3}$

La modernización del Derecho penal se argumenta por la supuesta aparición de nuevas realidades sociales riesgosas, producto de las normales actividades humanas en desarrollo de las innovaciones tecnológicas y de la forma de vida "evolucionada"; un ejemplo de esto es, precisamente, el deterioro ambiental por el desarrollo tecnológico, la alta participación de la industria y las formas de producción y consumo que impone el sistema económico imperante, realidades éstas que no es posible atribuir a la realización de conductas individuales porque el deterioro es la suma de muchos

2 Estas sociedades, también denominadas post-industriales, se consideran sociedades altamente desarrolladas, tanto en lo industrial como en lo tecnológico, razón por la cual los desarrollos doctrinales al respecto no son aplicables completamente al contexto colombiano; sobre esto véase a Arias (2006: 9). Esta situación también es reiterada por Beck (2006: 8), quien manifiesta que la globalidad de esos riesgos no implica la igualdad global de estos, de hecho son los países pobres los que reciben las mayores consecuencias; por eso insiste que "la contaminación sigue al pobre", que se ha aumentado la brecha entre ricos y pobres y los países más desarrollados han obligado a los países endeudados a que desarrollen industrias especializadas para abastecer adecuadamente a los primeros, lo que implica entonces el aumento de los riesgos también en los países tercermundistas.

3 Frente al medio ambiente este autor considera que es un bien o una realidad que por tradición era abundante, pero que ahora está escaso, lo que aumenta el valor que tradicionalmente se le otorgaba, manifestándose su valor a través de la protección penal. 
comportamientos humanos. De esta manera, el ius puniendi interviene sobre cada uno de los individuos, porque la sociedad pide controlar esas actividades riesgosas que generan sensación de inseguridad.

El Estado responde con su herramienta punitiva, que termina siendo usada como instrumento por excelencia para evitar la producción de tales riesgos antes que otros mecanismos de control social. Asunto que de entrada cuestiona, entre muchos otros aspectos, el principio de mínima intervención penal y la flexibilización de todo el sistema de garantías individuales que se ha construido alrededor del Derecho penal.

\section{CARACTERIZACIÓN DEL DERECHO PENAL QUE SE EMPLEA PARA LA TUTELA AMBIENTAL}

Quienes promueven la intervención penal para la tutela del medio ambiente y los recursos naturales, por la necesidad de enfrentar los riesgos a los que están expuestos en la actualidad, lo hacen en su mayoría aclarando que eso no debe implicar la flexibilización de las garantías jurídico penales que parecen acompañar la modernización del Derecho penal. ${ }^{4}$

Uno de los autores que avala esta intervención es Terradillos "quien defiende la conveniencia de la intervención penal en ciertos ámbitos como el económico, el medio ambiente, etc., pero sin que ello signifique una relativización de garantías" (Arias, 2006: 18). Otro de los defensores de la protección del ambiente por la vía penal es Muñoz, quien considera que se deben proteger bienes jurídicos colectivos como el medio ambiente, incluso de manera independiente de la vida, salud e integridad física de las personas, pero esto no lo defiende a cualquier costo, pues aclara que es necesario "que en la intervención del Derecho penal en esta materia se cumplan determinadas exigencias características del Derecho penal de un Estado social y democrático de Derecho" (Hassemer y Muñoz, 1995: 65).

$\mathrm{El}$ anterior punto de partida es importante en la medida que se quiere mostrar cómo, a pesar de las buenas intenciones de estos autores, la criminalización de conductas que atentan contra el medio ambiente, a través de la implementación de figuras como los bienes jurídicos colectivos de contenido difuso, los delitos de peligro abstracto, los delitos acumulativos y las normas penales en blanco, sí afectan el sistema de garantías penales.

4 Véase entre otros a Schünemann (1996), Terradillos (1999) y a Muñoz (Hassemer y Muñoz, 1995). 


\section{Bien jurídico colectivo: enfoques de protección ambiental y sus repercusiones en el Derecho penal}

Entender que el medio ambiente y los recursos naturales constituyen un bien jurídico, supone aludir a una entidad difícilmente identificable, de contenido difuso, que hace evanescer la función de garantía del principio de exclusiva protección de bienes jurídicos. Esta afirmación es válida siempre que se defienda que la protección del bien jurídico constituye un límite y la misión de la intervención penal. ${ }^{5}$

La consagración del medio ambiente y los recursos naturales como bienes jurídicos difusos genera la anticipación de la esfera de protección penal a conceptos que no alcanzan la entidad de bien jurídico; algunos autores aducen que se abandona el mencionado principio de exclusiva protección de bienes jurídicos por el reemplazo de la peligrosa preservación de meras funciones sociales. ${ }^{6}$

Por tal razón, se comparte la posición de Bustos cuando manifiesta que no es suficiente expresar conceptualmente la existencia de un bien jurídico si no se revisa su configuración práctica, porque con ello se está atentando, entre otros, con el principio garantista de necesidad de la pena, y en estos casos el bien jurídico no podrá cumplir la función de límite a la intervención punitiva (Bustos, 1991: 107).

Por lo demás, todas las críticas que pueden señalarse al bien jurídico medio ambiente son las mismas señaladas por la doctrina cuando se trata de

5 De manera muy breve deberá decirse que gran parte de la doctrina moderna reconoce la protección de bienes jurídicos como finalidad del Derecho penal, en la medida en que éstos deben contribuir en el proceso de selección de las conductas penalmente relevantes porque atentan contra objetos que merecen la tutela penal, basado en la idea utilitarista de que el Estado sólo puede intervenir con pena frente a las acciones que causan daños a las demás personas. En este sentido véase a Prieto (2003: 59), quien agrega que "de la teoría del bien jurídico tan sólo podemos esperar criterios negativos de deslegitimación que muestren la carencia de justificación de una determinada intervención penal, pues la presencia de un bien jurídico es una condición necesaria, pero no suficiente de la respuesta punitiva". Pero frente a la postura que defiende la protección de bienes jurídicos como tarea del Derecho penal, se encuentra otra que propone la protección de la vigencia de la norma, cuyo principal representante es Jakobs (1996). Este autor propone que la pena se imponga ante el quebrantamiento de la norma, porque la pena no repara bienes; ella debe confirmar la identidad normativa de la sociedad porque funciona como el mecanismo de comunicación de unas expectativas sociales que se ven defraudadas por el delito, entonces se requiere la pena para señalar que el Derecho no ha sido defraudado, que éste aún está vigente. De manera que para este autor lo decisivo no es la lesión al bien jurídico, el ataque externo o tangible, sino que la pena cumple un papel comunicativo: negar la negación de la norma. Véase también a Müssig (2001).

6 Entre otros véase a A. Baratta (1991: 49), Sessano (2002: 218 y 220), Bustos (1991: 104) y Hormazábal (1992: 53). 
los bienes jurídicos colectivos, esto es, dado que el medio ambiente es un bien jurídico colectivo resulta lógico que él reproduzca todas las tensiones que surgen cuando se trata de esta clase de objetos de tutela.

Existen dos posturas en torno a la dependencia o independencia que tienen los bienes jurídicos colectivos ${ }^{7}$ respecto de los intereses individuales. La primera puede verse, por ejemplo, con Schünemann (1996), que les otorga relevancia jurídico penal y les reconoce plena autonomía, en la medida en que éstos complementan los bienes jurídicos individuales y su afectación comporta una mayor dañosidad social frente a todas las generaciones y por esto su protección se presenta de manera previa.

La segunda postura es defendida por Hassemer (1995), que se opone a la anterior posición argumentando que los bienes jurídicos colectivos deben estar fundamentados materialmente en intereses individuales, por lo tanto, deben consagrarse siempre en función de la persona. En este mismo sentido, para Terradillos (1995) es innecesario buscar la autonomía de los bienes jurídicos colectivos, porque no es posible dejar de identificarlos con bienes individuales, en la medida que los colectivos son puentes para hacer viables los personales. ${ }^{8}$

7 Las características principales que han definido a los bienes jurídicos en su calidad de colectivos son expresadas por Soto (2003: 196), como de titularidad compartida, indisponibles e indivisibles. La titularidad de este tipo de bienes jurídicos recae sobre toda la sociedad, de manera compartida, razón por la cual se argumenta que no es posible disponer unilateralmente de ellos, por ejemplo, expresar consentimiento individual para la lesión o puesta en peligro del medio ambiente, porque quien intente disponer de él no es su único titular. En este punto particular habría que verificar lo que sucede con el bien jurídico medio ambiente frente a la posibilidad de que todos los miembros de la sociedad consentimos esa afectación, en parte por lo que ya se expuso sobre la necesidad de la explotación del mismo en el marco de la industrialización y el modelo económico, en donde se encuentran intereses en juego como la necesidad de consumo, de trabajo y de producción, pero habría que decir que "se entiende que el bien jurídico es indisponible por no poder verificarse el consentimiento de todos los cotitulares". Si se concluye entonces que no son disponibles, en el mismo sentido podrá decirse que no son indivisibles, porque recaen sobre todo un conjunto de personas sin posibilidad de dividirlo en partes y otorgarle cada una de ellas a cada una de las personas que conforman el conjunto social, piénsese, por ejemplo, si esto se permitiera con el medio ambiente.

8 De la misma manera, expresa Corcoy (1999: 205), que: "La consecuencia práctica de este doble presupuesto en la concepción e interpretación de los bienes jurídico-penales supraindividuales, entendidos como protección de intereses o derechos colectivos con referente individual, es que en la calificación de un hecho como punible siempre, cualquiera que sea el delito, se deberá interpretar el tipo teleológicamente en atención a estos dos fines y nunca formalmente. Se trata de negar la posibilidad de interpretar determinados delitos como delitos de mera desobediencia o de peligro presunto. Cualquiera de los tipos que la doctrina ha calificado como delito de mera desobediencia o de infracción de un deber están dotados de antijuridicidad material y lesividad si se interpretan los elementos típicos no formalmente sino teleológicamente, en atención al bien jurídico protegido". 
La postura que otorga valor a los bienes jurídicos colectivos, con independencia de la afectación de bienes de carácter individual, se considera más expansiva de la intervención penal que aquella que vincula la necesidad de protección de estos bienes a la vulneración de referentes individuales. En esta última se trata, entonces, de establecer una serie de exigencias para que el Derecho penal sea una herramienta idónea para la protección de cualquier bien jurídico, incluyendo al medio ambiente. Por esto, defender un referente personal en los bienes jurídicos colectivos no implica negar su autonomía, lo importante es que ellos cumplan con el requisito de materialidad, es decir, que puedan ser lesionados; pero además, es importante que no sean protegidos de cualquier modo y ante cualquier ataque. De manera tal que por un lado se podrían aceptar los bienes jurídicos colectivos, teniendo en cuenta que de forma mediata buscan proteger referentes personales, y por el otro se deben rechazar las propuestas modernizadoras del Derecho penal, que buscan proteger determinados intereses a cualquier costo o tutelar meras funciones (Sotomayor, 2009: 290-291).

Teniendo en cuenta los postulados de Ferrajoli (1995), es necesario expresar que una postura de Derecho penal mínimo debe contribuir a la disminución de los bienes jurídicos actualmente tutelados por el ordenamiento penal, lo que conlleva también a una masiva reducción de prohibiciones de la norma penal, como requisito de su legitimidad política y jurídica. Por esto, su propuesta, que aquí se hace extensiva, es la de considerar como bien jurídico, a la luz del principio de lesividad, una concepción más amplia que la de Feuerbach (bien jurídico reconducido a los derechos subjetivos), pero más restringida que la concepción mayoritaria en el ordenamiento penal.

Pero también es importante tener claro que la consagración del bien jurídico en el ordenamiento penal debe obedecer a un proceso previo y legítimo de protección de intereses esenciales para los individuos y su vida social y no que se trate de crear bienes jurídicos para poder sancionar conductas meramente molestas para la sociedad. ${ }^{9}$

9 En este punto Soto (2003: 169) expone que la necesidad de legitimar las normas penales a través de los bienes jurídicos implica analizar los criterios y valores con los que se identifican unos determinados grupos sociales: “[e]n una sociedad democrática y pluralista, las valoraciones sociales mayoritarias deben constituir, a mi entender, el referente normativo fundamental para la concreción legislativa de las formas de conducta intolerables por su dañosidad social, sin obviar el criterio delimitador que representa la Constitución", así mismo, agrega que ese referente externo no ha de ser, según el criterio de esta autora, el bien jurídico, ya que éste es solamente un mecanismo técnico jurídico que ayuda a sintetizar los presupuestos esenciales de la convivencia, que el Derecho penal selecciona para ser protegidos (170). 
La aceptación de la protección penal del medio ambiente y los recursos naturales se ha dado, en parte, por el deterioro al que se ha llegado, pero también por la importancia que se le ha dado desde los marcos constitucionales, ${ }^{10}$ razón por la cual gozan de amplio reconocimiento como bien jurídico colectivo. Esta medida penal se entiende como una manera de evitar la autodestrucción de la vida humana, en especial, por la manera como las generaciones presentes están desperdiciando el medio ambiente, con lo que niegan la posibilidad de disfrute a las generaciones futuras a quienes se les ha otorgado protección autónoma, al igual que al bien jurídico analizado.

La manera de abordar la tutela penal del ambiente reproduce el debate en torno a si es conveniente una protección autónoma de tal entidad o si es preferible defender la tutela del medio ambiente como un canal para satisfacer a los seres humanos, entendido como el centro de tutela jurídica, esto es, bienes jurídicos colectivos con referente individual.

\section{La concepción ecocéntrica o biocéntrica}

La autonomía o dependencia que se le otorga al bien jurídico colectivo medio ambiente y recursos naturales obedece a la adopción de un enfoque o una concepción ecocéntrica o antropocéntrica. ${ }^{11}$ Las visiones ecocéntricas o biocéntricas del medio ambiente parten de que "la "naturaleza' o la 'biósfera', con todos sus componentes -aire, mar, plantas y animales, etc.- son entidades autónomas, merecedoras, en cuanto tales de protección; el medio ambiente no es, en otras palabras, un medio, sino un fin en sí mismo, por lo que su tutela no se legitima en virtud de su funcionalidad para intereses personales, sino por su valor intrínseco (Al-

10 Esta situación es bastante clara en Colombia donde la Constitución actual (expedida en 1991) es conocida como la Constitución ambiental, por contener una amplia gama de artículos que hacen referencia a la importancia del tema ambiental, como son: la obligación del Estado y de las personas de proteger las riquezas naturales (Artículo 8), la función ecológica de la propiedad (Artículo 58), el derecho a la educación ambiental (Artículo 67), los derechos colectivos y del ambiente (artículos 78 a 82), la obligación de todos los colombianos de cumplir la Constitución y de proteger los recursos naturales (Artículo 95, Numeral 8), la explotación de los recursos naturales en territorios indígenas (parágrafo del Artículo 330) y la finalidad social del Estado de brindar saneamiento ambiental y agua potable (Artículo 366). Además, con la Constitución de 1991 se introduce el concepto de "desarrollo sostenible" (Artículo 80) como preocupación central de la planeación en el aprovechamiento de los recursos naturales y el medio ambiente, producto de ello nace la ley 99 de 1993.

11 Sobre esto véase Alcacer (2002) y Cadavid (2009: 265). 
cacer, 2002: 153-154)"; ${ }^{12}$ por lo tanto, de acuerdo a esta concepción, merecen amparo independiente y previo a la salvaguardia de cualquier bien personal, el medio ambiente, los recursos naturales y el equilibrio de los ecosistemas; incluso se argumenta que al tener como objeto de protección penal al medio ambiente se tutela también, aunque de manera indirecta, la vida de los individuos, pero ésta es una preocupación secundaria para la postura ecocéntrica.

\section{La concepción antropocéntrica}

Por su parte, la concepción antropocéntrica parte de que el hombre es la preocupación central del Derecho, por tanto, el medio ambiente ha de protegerse en la medida que garantice los bienes jurídicos individuales. En esta corriente algunos autores ni siquiera consideran el medio ambiente como bien jurídico. En palabras de Alcacer, en esta visión "la única razón por la que puede justificarse la protección del medio ambiente es la de su valor para los intereses humanos" (2002: 153). En Colombia se adopta una posición ecléctica (antropocentrismo moderado), ya que en algunos tipos penales ambientales se exige la puesta en peligro de la vida o salud humana, pero en su mayoría basta con la afectación de los componentes del medio ambiente que se protegen.

Dentro del antropocentrismo moderado encontramos la necesidad de protección de las generaciones futuras a través de la tutela penal ambiental, porque, para quienes defienden esta intervención, no basta sólo con proteger la vida y la salud de las personas pertenecientes a las generaciones presentes, por lo tanto, la protección del ambiente no puede abarcar sólo la puesta en peligro del momento, sino que debe evitar procesos de afectación a largo plazo para garantizar condiciones de vida digna a las generaciones futuras (Kindhäuser, 1998: 503). En este sentido, Alcacer (2002: 153) manifiesta que, aunque con la tutela penal del ambiente se protejan de manera mediata estas generaciones, ello no debe suponer que el Derecho penal

12 Este autor aclara que "la concepción puramente ecocéntrica -aquella que, motivada por los movimientos ecologistas más radicales, otorga al medio ambiente, en su conjunto, prácticamente un carácter de entidad viva independiente y, por ello, viene a considerarlo 'sujeto' de derechos- no es sostenida por ningún autor en la dogmática penal” (Alcacer, 2002: 154). Y más adelante expresa: "No hay, en suma, 'derechos del medio ambiente', ni, en rigor, tenemos 'deberes hacia el medio ambiente', sino que esos deberes vienen dados con relación a los derechos de los demás ciudadanos a unas condiciones tolerables de vida" (155). 
La protección penal ambiental: uso ilegítimo de las funciones simbólicas del derecho

deba asumirlas como objeto central y directo de protección, es decir, que la valoración del bien jurídico que se analiza se haga respecto de la necesidad de preservar las generaciones futuras. Este mismo autor plantea que:

Es evidente que los intereses de las generaciones futuras, en cuanto potenciales, no pueden encarnarse en bienes jurídicos personales como la vida, la integridad física o la propiedad, por lo que su protección no puede llevarse a cabo a través de la prohibición de lesionar esferas ajenas de libertad. Por el contrario, dicha protección sólo puede acometerse a través del mantenimiento actual de las condiciones de supervivencia futura; es decir, a través de la protección del medio ambiente (Alcacer, 2002: 152). ${ }^{13}$

Adicionalmente, la vulneración a este bien jurídico parece derivarse del "normal" funcionamiento del sistema social en ese marco de riesgos ambientales que se ha mencionado, en donde tienen mayor acogida las necesidades de progreso económico. A pesar de reconocer que se derivan de actividades permitidas y que se ven necesarias para el desarrollo social y económico, fundamentalmente se establecen ciertas prohibiciones con la finalidad de proteger el futuro de la humanidad, para conservar el medio ambiente en unas condiciones más o menos parecidas a las actuales, así es manifestado por Corcoy:

Con la protección del medio ambiente, la flora y la fauna se pretende [...] proteger el equilibrio de los sistemas naturales respecto de los riesgos de destrucción a corto plazo, pero también a medio y largo plazo,

13 Llama la atención en la exposición que hace este autor sobre la protección del medio ambiente para garantizar las condiciones de las generaciones futuras, en lo que se refiere a las estructuras de imputación que posee actualmente el Derecho penal, planteando que, para quienes avalan esta protección, deben ser modificadas en el marco del fenómeno expansivo del Derecho penal por la generación de riesgos que deben ser controlados para calmar la inseguridad que siente la sociedad. En este sentido, el autor expresa en este mismo texto: "Lo anterior, en consecuencia, llevará al establecimiento de una nueva orientación en las estructuras de atribución de la responsabilidad, desde la que se otorgará prioridad al poder causal de destrucción sobre la capacidad de previsión del agente en su obrar, tal y como de forma paradigmática se muestra en la 'ética orientada al futuro' propuesta por Hans Jonas en su obra El principio de responsabilidad. A juicio de este autor, es preciso desarrollar una conciencia de solidaridad hacia las generaciones futuras, para lo que sólo esa ampliación de la responsabilidad puede venir a modificar nuestra indiferencia moral hacia las mismas" (Alcacer, 2002: 159-160). Se considera relevante que el Estado lidere o se preocupe por el fortalecimiento de la conciencia solidaria, lo que no se comparte es que eso pretenda llevarse a cabo a través del Derecho penal, que debe tener como una de sus características principales actuar como ultima ratio. 
por cuanto, las consecuencias que puedan derivarse para el futuro del planeta no se conocen con certeza. Por ello, cuando veíamos la lesividad propia de los delitos contra los bienes jurídicos supraindividuales, advertíamos que "lesión" no puede confundirse con "destrucción", sino que equivale a "afectación", y en el caso del medio ambiente conocemos una afectación de presente, pero no se puede olvidar la posible afectación de futuro, que también debe de ser valorada al considerar la necesidad de incriminación de estas conductas (1999: 233-234).

La mayor dificultad que se encuentra en la protección de las generaciones futuras y del medio ambiente de manera autónoma y desligada de los bienes jurídicos personales radica, tal y como lo resalta Alcacer (2002: 160), en que se reconduzca la responsabilidad contaminante de carácter colectivo hacia acciones mínimas, bajo el entendido que los riesgos para aquellos surgen de la acumulación de actos individuales: "Que, siendo en sí inocuos, podrían llevar, si todos lo hiciéramos, a la destrucción futura del planeta o, por poner un ejemplo menos drástico y más factible a corto plazo, a la destrucción irreparable de los bosques húmedos del trópico". A este fenómeno se le conoce como daños acumulativos y supone que el bien jurídico medio ambiente y recursos naturales se proteja de acciones individuales, consideradas inocuas (esas conductas, incluso evaluadas de modo ex ante, no se consideran peligrosas) y que no producen la puesta en peligro de aquel, pero ante la repetición de estos comportamientos cada uno se percibe peligroso. En esta figura no se espera al momento de lesión o puesta en peligro abstracto porque esto podría suponer, si todas las personas lo hicieran, la destrucción total del bien jurídico, razón por la cual ha tenido tanto eco en la tipificación de las conductas ambientales.

En el caso concreto de la protección ambiental, como supone la expansión del Derecho penal, no se garantiza el principio de mínima intervención, en especial desde su aspecto fragmentario (protección de aquellos intereses imprescindibles para la vida social, pero frente a aquellos ataques especialmente fuertes o graves), es por esto que Prittwitz (2003: 263) expone que las conductas que se criminalizan por atentar contra el medio ambiente son delitos de bagatela - por ser efecto de la acumulación- y que por el afán de resolver problemas de carácter estructural se traspasan estos problemas para que los solucione el ius puniendi, sin analizar previamente los efectos colaterales que tal intervención puede implicar, porque "[u]na Ciencia Penal orientada a las consecuencias debe considerar al menos que también en el Derecho penal las buenas intenciones pueden originar malos resultados 
y que además, es posible que las consecuencias inadvertidas predominen sobre las queridas" (Prittwitz, 2003: 272).

El mencionado autor argumenta que el Derecho penal ambiental es ineficaz, lo que implica su fracaso, porque como ya se dijo, el deterioro del medio ambiente no se deriva de comportamientos considerados desviados sino a comportamientos ajustados a derecho en el marco de un proceso de producción en el contexto del modelo de desarrollo económico vigente, que cuenta con el aval del sistema jurídico y político, por lo tanto, este instrumento no va a funcionar si se está haciendo referencia a comportamientos que se consideran normales y permitidos, porque no contribuirá a su prevención (Prittwitz, 2003: 283).

De este modo, la discusión alrededor de cuál es el enfoque (ecocéntrico y antropocéntrico) preferible del medio ambiente como objeto de tutela, no es precisamente el problema central de la intervención penal ambiental, porque antes de ello hay que enfrentarse al cuestionamiento del instrumento penal como un medio no sólo inadecuado para tal finalidad sino incluso contraproducente.

En tal punto se debe enfatizar que la necesidad de satisfacer los requerimientos sociales (la protección de las generaciones futuras, disminuir el deterioro de los ecosistemas, etc.), no puede llevar a la ceguera de reivindicar un Derecho penal eminentemente simbólico y condenado al fracaso, porque a pesar de la cantidad de políticas públicas para la protección ambiental el deterioro no se detiene, especialmente por la realización de actividades que están permitidas.

\section{Derecho penal simbólico: eficacia en la protección del medio ambiente}

Sin duda uno de los rasgos de la intervención penal ambiental es su carácter simbólico. De hecho, muchas de las técnicas que emplea: peligro abstracto, delitos acumulativos y normas penales en blanco, confluyen o tienen como denominador común auspiciar en mayor o menor medida la apuesta por un Derecho penal eminentemente simbólico. Por ello, conviene detenerse en el debate en torno a este tema, pero antes, es importante precisar el aspecto conceptual.

Así, se puede decir que se plantean formas diferentes de comprender este concepto. Müller y Tuckfeld (1999) manifiestan que unos interpretan lo simbólico como ineficiente, otros como la puesta en escena de la política 
mostrando decisión y ganas de actuar pero sin efectos instrumentales, otros (como los seguidores de la teoría de la prevención general positiva) acentúan el carácter simbólico de todo Derecho, pues éste sigue vigente a costa del infractor, de manera que, "si lo que se busca es un criterio para la crítica éste puede obtenerse recurriendo al predominio de las funciones latentes frente a las manifiestas" (Müller y Tuckfeld, 1999: 524). ${ }^{14}$

Adicionalmente, es relevante anotar que las funciones simbólicas no se reducen sólo a que la norma penal no cumpla funciones instrumentales, porque lo simbólico se entiende como una estrategia general que implica la creación de normas para poner en ejecución un determinado objetivo político, lo cual puede suponer que la norma sí cumpla algunos efectos prácticos (García, 1991: 449).

Hassemer expresa que hay una dificultad en el concepto mismo de Derecho penal simbólico porque no ha sido objeto de estudio por la doctrina y por lo tanto no se encuentra un concepto preciso y apto de "simbólico" o "legislación simbólica". Lo que sí existe es un acuerdo global respecto de la dirección en la cual se busca el fenómeno de Derecho simbólico: "Se trata de una oposición entre 'realidad' y 'apariencia', entre 'manifiesto' y 'latente', entre lo 'verdaderamente querido' y lo 'otramente aplicado'; y se trata siempre de los efectos reales de las leyes penales. 'Simbólico' se asocia con 'engaño', tanto en sentido transitivo como reflexivo" (Hassemer, 1991: 28). De esta manera, el autor manifiesta que se requiere delimitar claramente lo simbólico, porque será muy diferente aducir que lo simbólico es un rasgo del Derecho penal, a decir que el Derecho penal es simbólico por excelencia.

\section{Argumentos a favor del Derecho penal simbólico}

La prevención general positiva se ha considerado la postura que más se dirige a la defensa de las funciones simbólicas del Derecho penal, su labor

14 Sobre las funciones latentes y manifiestas se expresan Zaffaroni, Alagia y Slokar (2006: 30), diciendo: "Que las leyes digan o declaren que regulan con un objetivo y en la realidad tengan otro resultado es bastante común y no por mala fe de los legisladores y ni siquiera de muchos intérpretes, pues en la mayoría de los casos el fenómeno se produce porque la realidad opera de modo diferente al imaginado. [...] Es necesario distinguir las funciones manifiestas de las instituciones (las declaradas o expresas) y sus funciones latentes (las que realmente cumple en la sociedad)". A la manera de pensar de los autores, el derecho penal debe ocuparse también de las leyes penales latentes y con ellas tiene dos opciones, o reconocerlas como verdaderas penas y cumplir en ellas los requisitos constitucionales o declararlas inconstitucionales y no seguirlas aplicando. 
va dirigida no a los infractores, sean actuales o potenciales, sino, en especial, a los ciudadanos fieles a la ley, porque se aduce que estos tienen una tendencia natural a respetarla con el fin de restablecer la confianza institucional que tienen en el ordenamiento jurídico, que se ve afectada por quien realiza una conducta considerada desviada. ${ }^{15}$

También se avala la función simbólica que desempeña el Derecho penal en aquellas áreas en las que antes éste no intervenía; así lo hace Corcoy (1999), ya que acepta la labor configuradora de valores de toda norma jurídica a pesar de que no esté probada la efectividad del Derecho penal para cumplir esa función; éste es precisamente uno de los efectos de la teoría de la prevención general positiva.

En todo caso, tal autora reconoce que la función simbólica es ilegítima cuando es la única que cumplen los tipos penales que protegen determinados bienes jurídicos (especialmente los de más reciente consagración y de carácter colectivo) (Corcoy, 1999: 201-202). ${ }^{16}$ No obstante, estima que es erróneo concebir que la intervención medio ambiental es ineficaz y sólo cumple efectos simbólicos.

Así, formulado este planteamiento es incorrecto en sus dos premisas, respecto de la primera, porque no está demostrada su inutilidad, ya que el Derecho penal puede ser eficaz también en estos ámbitos y, no sólo puede ser eficaz, sino que ya lo es actualmente. La pretendida ineficacia no puede fundarse en que se persiguen muy pocos de estos delitos ni en que se siguen realizando actividades delictivas en estos ámbitos, sino que debería de examinarse hasta qué punto la creación de estos nuevos delitos no está sirviendo ya para que muchos dejen de realizar estas actividades de forma delictiva, y para obligar a la Administración a tener un mayor cuidado en sus actuaciones (Corcoy, 1999: 200).

Parece entonces que con las medidas de protección penal ambiental se buscan efectos de prevención general positiva, es decir, como una herramienta de educación y de concientización, lo que lleva a que el Derecho

15 Defienden esta tesis, con distintos matices: Jakobs (1998), Müssig (2001) y Hassemer (1991).

16 La autora insiste en que no todo lo simbólico es negativo en el derecho y aclara que "[e]n relación con la aludida ineficacia del Derecho penal en estos ámbitos se advierte que es más una cuestión de falta de voluntad política de que intervenga el Derecho penal y de falta de los medios necesarios para su aplicación, que de una incapacidad de los instrumentos propios del Derecho penal para proteger a la sociedad frente a estos nuevos riesgos" (Corcoy, 1999: 370). 
tenga unos efectos simbólicos, que la teoría de la prevención general positiva ve como una característica esencial y normal de todo Derecho. ${ }^{17}$

\section{Argumentos en contra del Derecho penal simbólico}

A la prevención general positiva se le han planteado múltiples objeciones, una de ellas es que no se genera una seguridad real para los bienes jurídicos, porque se centran en brindar una respuesta simbólica a la demanda de seguridad por parte de la opinión pública. Entonces, propuestas legales de reforma (protección penal ambiental) como la que se analiza terminan siendo programas de decisión que no se orientan a modificar la realidad, sino a modificar la imagen de la realidad en esa opinión pública. ${ }^{18}$

Pero la crítica más importante que puede plantearse a estas posturas hace referencia a que no generan conciencia sobre el problema de fondo, por lo tanto, una de las finalidades latentes de la norma penal ambiental es crear la sensación de que se está protegiendo, mientras en realidad no se cumple esta tarea, la cual supone revisar las relaciones de producción y consumo. En definitiva, modificar el sistema económico para establecer unas relaciones menos depredadoras con los recursos y formar conciencia para el replanteamiento de estas estructuras. Lo anterior supone que el Derecho penal ambiental haya fracasado en su función real e instrumental de protección del bien jurídico y que por lo tanto cumpla funciones simbólicas ilegítimas, o que se le entienda como Derecho penal simbólico en sentido negativo.

Ello ocurre porque el Derecho penal siendo ineficaz, muestra una falsa efectividad o unos beneficios aparentes, al ser utilizado como una herramienta para que los individuos introyecten y aprendan la necesidad de protección

17 En este sentido afirma Ferrajoli (1995: 275) que la prevención general positiva es una expresión que busca reforzar la fidelidad hacia el Estado y la promoción de la conformidad de los comportamientos, porque conciben el Derecho penal como un instrumento necesario encargado por excelencia de la "orientación moral" y la "educación colectiva".

18 Al respecto véase a Baratta (1991: 53), ya que expresa que: "Su eficacia es estudiada, en efecto, a la luz de estas teorías, considerándola no tanto como un sistema de producción de seguridad real de los bienes jurídicos, sino más bien, como instrumento de respuesta simbólica (y precisamente, en este sentido, tecnocrático) a la demanda de pena y seguridad por parte del 'público' de la política, pero eso corresponde a lo que sucede en la realidad de la política criminal y de la política en general, cuando en ésta la 'comunicación política de base' se presenta entre ciudadanos y entre ciudadanos y sus representantes. [...]. En efecto, en la 'política como espectáculo' las decisiones y los programas de decisión se orientan no tanto a modificar la realidad, cuanto a modificar la imagen de la realidad en los espectadores: no tanto a satisfacer las necesidades reales y la voluntad política de los ciudadanos como más bien, a seguir la corriente de la llamada opinión pública”. 
del medio ambiente. Si esto se justifica entonces será posible que faltando el cumplimiento de las funciones instrumentales se podría legitimar igualmente la intervención penal, aunque ésta sólo cumpla una función simbólica.

Posiciones como la de la Escuela de Frankfurt rechazan la criminalización de conductas con esta finalidad, porque el Derecho penal termina protegiendo necesidades de organización social, política y económica. ${ }^{19}$

Desde una concepción como la que aquí se defiende, parece imposible adscribirse a la defensa de que el Derecho penal ambiental busque legítimamente producir efectos simbólicos, especialmente, debe negarse que sea plausible que la pena busque fines de prevención general positiva. No se trata de negar que es urgente emprender la tarea pedagógica en torno a la solidaridad con las generaciones futuras, y concientizar acerca de la necesidad de protección en torno al medio ambiente, lo que se discute es que esto pueda alcanzarse a través de la herramienta punitiva y, más allá de esto, que sea lícito que el Derecho penal persiga tales cometidos.

\subsubsection{Funciones simbólicas y funciones instrumentales}

La función instrumental exige la protección real del bien jurídico previsto en el precepto penal, lo que requiere que se den unas condiciones objetivas de realización de la norma para que sea eficaz, produciendo determinada modificación de la realidad social mediante la prevención de comportamientos dañosos. La función simbólica implica que las normas cumplan otra labor que no incide, al menos de modo inmediato, sobre la realidad externa, sino sobre la conciencia de los destinatarios de la norma para generar determinadas

19 La Escuela de Frankfurt tiene un punto de partida común, pero en ella se agrupan diversos autores que no siempre coinciden en todos los extremos, así lo expresa Silva (1999: XII): "Como es sabido, dicha 'escuela' no existe como tal; y en el seno del grupo de profesores de Frankfurt se dan evidentes diferencias ideológicas y metodológicas". Un autor adscrito a tal escuela es Hassemer (1991: 26) quien, en todo caso, en su análisis sobre el Derecho penal simbólico acepta que en principio no es reprochable el reconocimiento de que las normas penales tienen estos efectos, pero sí insiste en que lo importante es que la norma penal no debe cumplir sólo funciones simbólicas. Así mismo, presenta una lista de leyes que a su modo de ver cumplen diversas funciones simbólicas: "Leyes de declaración de valores (ejemplo: aborto, entre la exigencia moral de la mujer a su determinación y descendencia por un lado y la confirmación de la prohibición de matar por otro lado), Leyes con carácter de apelación (moral) (ejemplo: Derecho penal del medio ambiente con el objeto de dotar de conciencia ecológica a las personas que ocupan posiciones relevantes -StGB-), Respuestas sustitutorias del legislador: leyes que sirven de coartada, leyes de crisis (ejemplo: leyes en contra del terrorismo con el objeto de por lo menos tranquilizar el miedo y las protestas públicas), Leyes de compromiso (ejemplo: cláusulas penales generales, las que si bien son poco decisorias siempre tiene un núcleo central para satisfacer la 'necesidad de actuar')" [la negrilla no es del original]. 
representaciones valorativas. Esta última resulta en cierta medida consustancial a la ley penal, y según Soto Navarro no obstaculiza el logro de la función instrumental; antes al contrario, la refuerza (Soto, 2003: 187).

Ahora bien, existe una estrecha y contradictoria relación entre funciones simbólicas e instrumentales que se vuelve más problemática cuando las primeras empiezan a prevalecer sobre las segundas, porque empieza a fallar la protección real de los bienes jurídicos; pero esta carencia se suple sin problema a través de la creación de ilusión de seguridad y confianza en el ordenamiento jurídico y "en las instituciones que tienen una base real cada vez más escasa: en efecto, las normas continúan siendo violadas y la cifra obscura de las infracciones permanece altísima mientras las agencias de control penal siguen midiéndose con tareas instrumentales de imposible realización por ese hecho: piénsese en la defensa de la ecología" (Baratta, 1991: 53).

De tal manera, se empiezan a ver negativamente las funciones simbólicas cuando ellas quieren reemplazar o primar respecto de las instrumentales, y es allí donde comienza a hablarse de Derecho penal simbólico en un sentido negativo, lo que exige un análisis crítico para intentar desentrañar la razón por la cual el concepto que tiene un significado neutral (en la medida que se constituye en una de las características del Derecho penal) deviene peligroso.

En consecuencia, las funciones simbólicas van ganando más independencia respecto de la solución real del problema ambiental que enfrenta el mundo, porque, frente a la crisis de las funciones instrumentales - protección real del medio ambiente y los recursos naturales- y en especial, aprovechando la alarma social que se ha generado por su deterioro, lo que se hace es buscar la obtención del consenso por parte de la opinión pública (Baratta, 1991: 54). ${ }^{20}$

20 Antes de continuar con el análisis concreto del Derecho penal ambiental de carácter simbólico es importante recordar que a todo el Derecho se le otorga una cierta carga simbólica, de hecho en el contexto latinoamericano (García y Rodríguez 2003: 23), dicen que es propia la característica de la ineficacia jurídica, que trae a su lado esa función simbólica. Así mismo, manifiestan: "[1] a ineficacia hace alusión a la diferencia entre lo establecido por el derecho, de un lado, y la conducta de los actores del campo jurídico y de la ciudadanía en general, del otro. [...] se trata de la brecha entre norma y práctica, de la escasa penetración del derecho -particularmente del derecho estatal- en la práctica social cotidiana”. Estos autores abordan el concepto de campos jurídicos latinoamericanos para incluir en este espacio jurídico, “-además de las normas- a los actores, símbolos, ideas, relaciones de poder e instituciones sociales que constituyen la práctica del derecho (García y Rodríguez, 2003: 19)" [la negrilla no es del original]. Precisamente, por esta dinámica entre los diferentes intervinientes esos campos jurídicos son complejos y los autores consideran que tienen los siguientes tres rasgos característicos: la pluralidad, la ineficacia y el autoritarismo. Cuando los autores hacen mención de los campos jurídicos latinoamericanos lo hacen partiendo del concepto de campo jurídico de Bourdieu, como el espacio mental en que se puede hacer la idea de la realidad, entendido como un campo poroso que permite interacciones de sus actores, lo que a su vez facilita la diversificación del campo mismo. 
Se ha dicho que la ineficacia jurídica y las funciones simbólicas del Derecho son causadas en parte por el reformismo jurídico y son usadas como herramienta de poder para solucionar problemas sociales, o mostrar que hay algún interés en solucionarlos. Con esto se produce una congestión en la vía jurídica en labores que le corresponden al campo político, descuidando la función instrumental de las normas jurídicas (tener una función real en la sociedad) para cumplir con los efectos simbólicos o de comunicación. ${ }^{21}$

Ahora bien, lo que ocurre con las funciones simbólicas no es que no se produzcan efectos materiales sino que no se producen aquellos efectos materiales para los que dice estar prevista la norma, fundamento principal del legislador para crearla. Así las cosas, lo que se busca es una "comunicación legitimadora entre las instituciones, de un lado, y los actores del campo jurídico y los ciudadanos en general, del otro, más que para satisfacer sus objetivos instrumentales declarados" (García y Rodríguez, 2003: 43), por lo que se dice que puede alcanzar objetivos (incluso ilegales) no reconocidos en la norma.

En tal sentido, García manifiesta que las normas se crean esperando que su promulgación genere determinadas representaciones colectivas, a través de las cuales las instituciones estatales obtienen beneficios; entonces no se trata de que las normas fracasen por ser ineficaces, sino todo lo contrario, terminan siendo un éxito (1991: 420) porque esa ineficacia instrumental de las normas de protección ambiental tiene de por medio intereses políticos, razón por la cual se sustituyen los fines declarados en las normas por unos no explícitos en sus textos. Esta cuestión se agrava al realizarse con normas penales, porque además de implicar esos efectos simbólicos indeseables tiene unos efectos reales en la vida de las personas de carne y hueso que resultan condenadas por esas prohibiciones. ${ }^{22}$

21 Al respecto García y Rodríguez (2003: 43) aclaran, en el tema de la eficacia simbólica, que eso no quiere decir que todas las reformas estén encaminadas a legitimar la acción del Estado, ni que todas las normas con fines simbólicos no tengan la posibilidad de cierta eficacia instrumental, o que si fracasa es porque cumplía funciones simbólicas.

22 Respecto de las funciones latentes y manifiestas, García (1993: 84,85) expone: "Según Merton, las ceremonias indígenas de la lluvia o de la fertilidad, por ejemplo, no producen lluvia y no aumentan los nacimientos, pero tienen la función latente, no declarada, de reforzar la identidad del grupo. [...] Sin embargo, al definir la función latente Merton demuestra cierta ambigüedad al no aclarar si ella tiene el carácter de una función colateral, no esperada y ajena a los propósitos del sujeto o si, en cambio, resulta de una intención implícita, no declarada, del sujeto actuante. Todo parece indicar que ambos casos, según Merton, se encontrarían englobados dentro del concepto de función latente". Así mismo, expresa el autor que "[e]l derecho ordena, forma e informa no solamente a través del sentido explícito de sus textos y ritos, sino también a través de su misma producción y de su propio consumo. [...] Al momento de explicar la incidencia social del derecho hay que tener en cuenta no sólo el hecho de que existen funciones latentes que también dan cuenta de la razón de ser y de la producción del 


\section{Conclusiones: Derecho penal simbólico ilegítimo}

Se ha dicho que la función simbólica del Derecho penal se torna ilegítima cuando ésta es la única finalidad de intervención, pero se defiende siempre y cuando vaya acompañada de una función instrumental, es decir, de modificación de la realidad. En este sentido Baratta manifiesta que esa pretendida función instrumental del Derecho sólo ha servido para desplazar los límites del ius puniendi y para ocultar las funciones simbólicas y políticas de la acción punitiva, además de contribuir a sostener la pena como violencia institucional necesaria, pero allí se acompaña de una función latente que consiste en reproducir el subsistema de justicia penal y servir a la producción ideológica y material de las relaciones sociales desiguales (1991: 54).

La función simbólica de las normas penales cumple un papel importante en los intereses políticos frente a la necesidad de la sociedad respecto al tema ambiental, porque la sociedad se ha formado una idea de lo que se requiere para la tutela del medio ambiente y los recursos naturales a través de la formación de la "opinión pública" que surge como la opinión dominante generada en los medios de comunicación masiva, de tal manera que es construida por esos medios de comunicación ya que determinan el sentido $\mathrm{y}$ alcance de los atentados ambientales que merecen ser criminalizados. ${ }^{23}$

En lo que tiene que ver particularmente con la regulación penal del medio ambiente, se insiste en que ésta es una de las áreas del Derecho penal

derecho, sino también que las funciones manifiestas no siempre logran tener eficacia y que, en ocasiones, dicha ineficacia es ella misma una función latente". En el contexto penal, podemos decir de la mano de Hassemer (1991), que las funciones manifiestas son aquellas condiciones objetivas que permiten la realización de la norma, y lo que buscan es garantizar la protección del bien jurídico que allí se consagra. En cambio, las funciones latentes, que pueden ser muchas y muy diferentes, suelen ser aquellas que buscan la tranquilidad social, satisfacer la necesidad de la población hacia un actuar estatal, mostrar un Estado fuerte e intervencionista, etc.; si predominan las segundas se configura lo que este autor denomina engaño o apariencia.

23 En este sentido, González (2010: 101-102) expresa que existe un relativo consenso entre autores como Elena Larrauri, José Luis Díez Ripollés y David Garland sobre las dos acepciones que puede tener el concepto de populismo punitivo: por un lado y siguiendo la propuesta de Larrauri, se entiende que es la utilización de la herramienta penal por parte de los políticos para fines electorales, para obtener consenso moral en la sociedad, beneficios electorales y porque parece necesario instaurar mayores penas para evitar el delito. Un segundo entendimiento del concepto hace referencia a la creencia de que el delito es un asunto de todos y que, por lo tanto, debe ser resuelto igualmente, razón por la cual se acude al sentido común para decidir el camino de las normas penales y se desdeña la labor de los académicos y expertos en este tema, porque esos problemas le atañen a todos los ciudadanos del común. 
que más carga simbólica posee y que menos efectos instrumentales cumple en la práctica, así lo expresa claramente Cadavid:

En efecto, en un país como Colombia, aquejado por un cruento y prolongado conflicto armado interno, y por apremiantes necesidades de crecimiento económico, la protección penal del medio ambiente tiene en la práctica un papel que ni siquiera alcanzaría a calificarse de secundario, resultando excesivamente amplio el espacio de riesgo permitido de las actividades que atentan contra él. Por ello es posible señalar que a pesar de la trascendencia que a nivel normativo y jurisprudencial se le reconoce a este bien jurídico, la efectividad de su protección se ha visto postergada por la incapacidad del Estado de aplicar en todo su territorio las prohibiciones normativas, que no alcanzan a sujetos que ostentan poderes fácticos derivados del uso de la fuerza o de la capacidad económica, y con frecuencia de ambos, como en el caso de quienes financian con el narcotráfico otras actividades ilícitas (2009: 259).

Müller y Tuckfeld (1999: 524) plantean la dificultad en la concepción de Derecho penal simbólico, porque, quienes están a favor de la protección del medio ambiente encontrarán que no es suficiente con que el Derecho penal cumpla aquí sólo una función simbólica, y entonces podrán decir que se incriminen más conductas buscando más Derecho penal en lugar de sólo Derecho penal simbólico; o que, de manera acrítica pretendan legitimar el Derecho penal precisamente por su función simbólica, como aquellos que consideran que puede emplearse como medio para la educación.

De la mano de estos dos autores se puede concluir que lo cuestionable "es la clase de mensaje que se transmite. El problema principal no es que el Derecho penal del medio ambiente sea ineficaz para impedir la contaminación ambiental, sino que su mensaje -en la medida en que se cree en élimpide una política ambiental racional y totalmente efectiva. [...] De este modo se oculta que nos encontramos ante un problema social relacionado con las formas de producción" (Müller y Tuckfeld, 1999: 525).

El modo que se ha practicado para la protección del medio ambiente, en especial a través de la intervención penal, no resuelve el problema de fondo que surge precisamente de la contradicción entre la necesidad de protección frente a un proceso de deterioro agresivo que obedece al modelo de desarrollo económico que conlleva la "exigencia" de un excesivo consumo e implica, por lo tanto, una exagerada producción. 
Para darle fin a este escrito se dirá, entonces, que la política criminal ha establecido unas figuras improcedentes para garantizar la protección ambiental porque sacrifican las libertades que pretenden garantizar un Derecho penal liberal, pero que cumplen una función simbólica única y por lo tanto ilegítima porque sólo ejercen una labor de tutela aparente que lo único que logran es causarle más daño a la efectiva salvaguardia de la naturaleza.

Tal situación desemboca en el fracaso del Derecho penal ambiental y de todas las políticas ambientales, además, porque mientras no existan intenciones reales de mermar la producción y el consumo y de frenar los procesos de alto deterioro, como se ve por ejemplo en la actividad de extracción minera o con las fumigaciones aéreas a los cultivos ilícitos, entre muchos otros casos, no existirá una posibilidad real de tutela del medio ambiente y de los recursos naturales.

Es así como, siguiendo la propuesta de Baratta, se dirá que el reto debe consistir en ubicar al Derecho penal perteneciente a un Estado social y democrático de Derecho, en un lugar en el que pueda ser coherente con sus principios garantistas, lo que supondría aplicarlo, transformarlo y reducirlo de conformidad con esos principios. Lo anterior significa aplicar rigurosa y técnicamente los límites de intervención, porque "lo que tal vez en un tiempo parecía una función útil [...] hoy, cada vez más, aparece como la violencia inútil de las penas. Esto presupone un uso instrumental del Derecho penal liberado de la ilusión de la instrumentalidad de la pena" (Baratta, 1991: 55).

\section{REFERENCIAS BIBLIOGRÁFICAS}

Alcacer, R. (2002). "La protección del futuro y los daños cumulativos". Revista Electrónica de Ciencia Penal y Criminología. Núm.4.

Arias, D. (2006). "A propósito de la discusión sobre el Derecho Penal 'moderno' y la sociedad del riesgo”. Cuadernos de Investigación. Núm.42, pp. 1-53.

Baratta, A. (1991). "Funciones instrumentales y simbólicas del Derecho penal: una discusión en la perspectiva de la criminología". Pena y Estado. Núm. 1, pp. 13-55.

Beck, U. (2006). La sociedad del riesgo global. Madrid: Siglo XXI.

Bustos, J. (1991). "Necesidad de la pena, función simbólica y bien jurídico medio ambiente”. Pena y Estado. Núm. 1, pp. 101-109. 
Cadavid, A. (2009). "La protección penal del medio ambiente en el Derecho Penal colombiano". En: A. Nieto y O. Mejía (eds.). Estudios de Derecho penal económico. Ibagué: Universidades de Castilla - La Mancha e Ibagué.

Corcoy, M. (1999). Delitos de peligro y protección de bienes jurídico-penales supraindividuales. Nuevas formas de delincuencia y reinterpretación de tipos penales clásicos. Valencia: Tirant lo Blanch.

Ferrajoli, L. (1995). Derecho y razón. Teoría del garantismo penal. Madrid: Editorial Trotta.

García, M. (1991). "Eficacia simbólica y narcotráfico". Nuevo Foro Penal. Núm.54.

(1993). La eficacia simbólica del derecho. Examen de situaciones colombianas. Bogotá: Universidad de los Andes.

García, M. y C. Rodríguez, (2003). "Derecho y sociedad en América Latina: propuesta para la consolidación de los estudios jurídicos críticos". En: M. García Villegas y C. Rodríguez Garavito (eds.). Derecho y sociedad en América Latina: un debate sobre los estudios jurídicos críticos. Bogotá: ILSA.

González, J. (2010). "La criminalización de la crítica". Estudios Políticos. Núm. 36.

Hassemer, W. (1991). "Derecho penal simbólico y protección de bienes jurídicos”. Pena y Estado. Núm. 1.

Hassemer, W. y F. Muñoz (1995). La Responsabilidad Penal por el producto en Derecho Penal. Valencia: Tirant lo Blanch.

Hormazábal, H. (1992). "Delito ecológico y función simbólica del Derecho penal". En: J. M. Terradillos (ed.). El delito ecológico. Madrid: Editorial Trotta.

Jakobs, G. (1996). Sociedad, norma y persona en una teoría de un derecho penal funcional. Bogotá: Universidad Externado de Colombia.

Externado de Colombia. (1998). Sobre la teoría de la pena. Bogotá: Universidad

Kindhäuser, U. (1998). "Elementos fundamentales del Derecho penal medioambiental". Revista de Ciencias Penales. Vol.1. Núm.2.

Müller, J. y M. Tuckfeld (1999). "Ensayo para la abolición del Derecho penal del medio ambiente". En: C. M. Romeo (ed.). La insostenible situación del Derecho Penal. Granada: Editorial Comares.

Müssig, B. (2001). Desmaterialización del bien jurídico y de la política criminal. Sobre las perspectivas y los fundamentos de una teoría del 
bien jurídico crítica hacia el sistema. Bogotá: Universidad Externado de Colombia.

Prieto, L. (2003). "Una perspectiva normativa sobre el bien jurídico". Nuevo Foro Penal. Núm. 65, pp. 46-91.

Prittwitz, C. (2003). "Sociedad de riesgo y Derecho penal". En: L. Arroyo, U. Neumann y A. Nieto (eds.). Crítica y justificación del Derecho penal en el cambio de siglo. El análisis crítico de la Escuela de Frankfurt. Cuenca: Universidades de Castilla - La Mancha.

Schünemann, B. (1996). Consideraciones críticas sobre la situación espiritual de la ciencia jurídico-penal alemana. Bogotá: Universidad Externado de Colombia.

Sessano, J. C. (2002). "La protección penal del medio ambiente. Peculiaridades de su tratamiento jurídico". En: V. Giménez (ed.). Justicia ecológica y protección del medio ambiente. Madrid: Editorial Trotta.

Silva, J. M. (1999). "Prólogo a la edición española". En: C. M. Romeo (ed.). La insostenible situación del Derecho penal. Granada: Universidad Pompeu Fabra.

(2006). La expansión del Derecho penal. Aspectos de la política criminal en las sociedades postindustriales (2. ${ }^{\mathrm{a}}$ ed.). Buenos Aires: Euros Editores.

Soto, S. (2003). La protección penal de los bienes jurídicos colectivos en la sociedad moderna. Granada: Editorial Comares.

Sotomayor, J. (2009). “¿El Derecho penal garantista en retirada?”. En: A. L. Calle (ed.). El estado actual de las ciencias penales. Bogotá: Ibáñez.

Terradillos, J. M. (1995). Derecho penal de la empresa. Madrid: Editorial Trotta. (1999). "Peligro abstracto y garantías penales". Nuevo Foro Penal. Núm. 62, pp. 67-94.

Zaffaroni, E.; A. Alagia y A. Slokar (2006). Manual de Derecho penal. Parte general. Buenos Aires: Ediar. 